Vol 11, Issue 4, 2018

\title{
OUTCOME OF PONSETI METHOD IN TREATING CONGENITAL IDIOPATHIC CLUBFOOT: FIVE YEARS' EXPERIENCE AT A TERTIARY HOSPITAL
}

\author{
EDEWET DAUN $^{1}$, MOHD YAZID BAJURI ${ }^{1}$, ABDUL HALIM ABD RASHID ${ }^{1}$, SHARAF IBRAHIM ${ }^{1}$, SRIJIT DAS $^{2}$
}

${ }^{1}$ Department of Orthopaedic and Traumatology, Faculty of Medicine, Universiti Kebangsaan Malaysia Medical Centre, Kuala Lumpur, Malaysia. ${ }^{2}$ Department of Anatomy, Faculty of Medicine, Universiti Kebangsaan, Malaysia Medical Centre, Kuala Lumpur, Malaysia. Email: ezeds007@yahoo.com.my

Received: 25 October 2017, Revised and Accepted: 21 December 2017

ABSTRACT

Objective: The earliest non-surgical treatment for the correction of congenital idiopathic talipes equinovarus (CTEV) deformity was described by Ignacio Ponseti. He suggested gentle manipulation and serial applications of casts followed by a period of bracing to maintain the correction. The main objective of this study was to evaluate the result of the Ponseti method with a subjective clinical scoring system using Pirani score, to compare the results with the published literature and to evaluate the effectiveness of foot abduction orthosis (FAO) or ankle-foot orthoses (AFO) in preventing relapse following correction.

Methods: A cross-sectional study which was conducted at the Paediatric Orthopaedic Clinic, Universiti Kebangsaan Malaysia Medical Centre (UKMMC). A minimum of 12 months follow-up casting was observed before the patient was subjected to the subjective clinical scoring system. A total of 25 patients which included 5 right feet, 9 left feet, and 10 bilateral feet with idiopathic clubfeet were treated with Ponseti serial casting. Percutaneous Achilles tendon tenotomy was done for 28 feet (82.35\%) to correct the equinus to achieve full correction.

Results: Our results showed that the Ponseti method for treating CTEV was comparable to other published studies. Satisfactory and good results were observed in $97 \%$ of cases. A total of $41.18 \%$ underwent re-tenotomy of tendon Achilles due to recurrent and persistent equinus.

Conclusion: The treatment of CTEV using Ponseti method will increase the successful correction. Meanwhile, the FAO gave better results for maintenance and prevention of recurrent deformity, compared to the AFO.

Keywords: Orthopedics, Ponseti method, Congenital idiopathic clubfoot.

(C) 2018 The Authors. Published by Innovare Academic Sciences Pvt Ltd. This is an open access article under the CC BY license (http://creativecommons. org/licenses/by/4. 0/) DOI: http://dx.doi.org/10.22159/ajpcr.2018.v11i4.23322

\section{INTRODUCTION}

CTEV is an in utero medial plantar displacement of the talonavicular and calcaneocuboid joint [1]. It is the most common childhood foot deformity which requires surgical treatment. The foot deformity is a three-dimensional deformity, which consists of four components, i.e., equinus, varus, adduction, and cavus deformities $[1,2]$.

The etiology of CTEV is still not well understood. The word talipes is derived from Latin; talus (ankle) and pes (foot). It is also known as clubfoot as severe untreated CTEV has a club-like appearance. Clubfoot is mentioned in the old Indian prayer book Yajurveda dating back to the $10^{\text {th }} \mathrm{BC}$. Hippocrates (460-377 BC) provided us with the oldest written description of clubfoot and its treatment. He used manual manipulation and bandaging to achieve and maintain correction [1].

Ignacio Ponseti first described his technique of manipulation and serial applications of cast in 1963 [3]. His results were very good avoiding the need for surgery in $89 \%$ of his cases. The Ponseti method of clubfoot treatment has gained popularity over the past few decades.

The rationale of the present study was to evaluate the result of the Ponseti method with a subjective clinical scoring system using the Pirani score and to compare our results with other published results. This study also aimed to evaluate the effectiveness of foot abduction orthoses (FAO) using Denis Browne shoes with bar compared to the ankle-foot orthosis (AFO) in preventing relapse following correction of idiopathic clubfoot by the Ponseti method.

\section{METHODS}

This was a cross-sectional study which was conducted at the Paediatric Orthopaedic Clinic, Universiti Kebangsaan Malaysia Medical Centre
(UKMMC). It was a 5-year study from June 2005 to December 2009 (Fig. 1). Patients were contacted for a follow-up appointment by mail or telephone. Clinical examination and subjective scoring using the Pirani score were done [4]. The outcome was measured using the Pirani score and parent's perception questionnaire at the end of the treatment (Table 1). The results were directly compared to previous results published in the literature which used the Ponseti method in treating congenital idiopathic clubfoot.

The inclusion criteria for this study were all patients diagnosed with congenital idiopathic clubfoot presented to the clubfoot clinic or who underwent Achilles tendon tenotomy (identified through operation book database) at UKMMC. A minimum of 12 months follow-up casting was observed before the patient was subjected to the subjective clinical scoring system and the patient could independently stand and had no soft tissue release done before treatment. The exclusion criteria were other established causes of clubfoot, e.g., such as neuromuscular disease, syndromic child, and teratologic clubfoot.

The Ponseti method is divided into two phases: The treatment phase, during which gentle manipulation of clubfoot and application of weekly serial casting until the deformity is corrected completely and the maintenance phase, during which a foot brace is applied to prevent relapse of the foot deformity. This weekly change serial casting usually takes about 5-6 weeks to achieve the correction with or without a minor surgical procedure to lengthen the Achilles tendon using percutaneous tendon Achilles tenotomy.

During this period, 37 children with 53 clubfeet received treatment in our center. We excluded 12 children who did not meet the inclusion criteria, 6 children (10 feet) had syndromic conditions or neuromuscular disorders, and another 6 children ( 9 feet) had defaulted follow-up. We reviewed the medical records of 25 infants (34 clubfeet), 
Table 1: Pirani score used for clubfeet assessment

\begin{tabular}{|c|c|c|}
\hline Hindfoot contracture score & Score & Description \\
\hline \multirow[t]{3}{*}{ Severity of PC } & 0 & Multiple fine creases \\
\hline & 0.5 & 1 or 2 deep creases \\
\hline & 1 & Deep creases changes contour of the arch \\
\hline \multirow[t]{3}{*}{ The emptiness of the heel (EH) } & 0 & Tuberosity of calcaneus easily palpable \\
\hline & 0.5 & Tuberosity of calcaneus more difficult to palpate \\
\hline & 1 & Tuberosity of calcaneus not palpable \\
\hline \multirow[t]{3}{*}{ The rigidity of equinus (RE) } & 0 & Ankle dorsiflexes fully \\
\hline & 1 & of $90^{\circ}$ or less \\
\hline & & $\begin{array}{l}\text { Ankle dorsiflexion severity limited. Lateral border of foot and leg make } \\
\text { an angle of than } 90^{\circ}\end{array}$ \\
\hline Mid foot contracture score & Score & Description \\
\hline \multirow[t]{3}{*}{ Severity of MC } & 0 & Multiple fine creases \\
\hline & 0.5 & 1 or 2 deep creases \\
\hline & 1 & Deep creases change contour of the arch \\
\hline Palpation of lateral part of the head of the talus (LHT) & 1 & Navicular does not reduce, lateral talar easily felt \\
\hline \multirow[t]{3}{*}{ CLB } & 0 & Straight border \\
\hline & 0.5 & Mild distal curved border \\
\hline & 1 & Lateral border curves at calcaneocuboid joint \\
\hline
\end{tabular}

MC: Medial crease, PC: Posterior crease, LHT: Lateral head of talus, CLB: Curvature of lateral border

Table 2: Patients characteristic and number of clubfeet treated with Ponseti method and $1^{\text {st }}$ percutaneous TA tenotomy, types of orthosis applied to prevent recurrence, types of clubfoot relapse and subsequent repeated $2^{\text {nd }}$ percutaneous TA tenotomy

\begin{tabular}{|c|c|c|c|c|}
\hline \multirow[t]{2}{*}{ Unilateral foot=14 (right $n=5$, left $n=9$ ) } & \multirow[t]{2}{*}{ Bilateral feet $n=10$} & \multicolumn{2}{|c|}{ Clubfoot } & \multirow[t]{2}{*}{ Total } \\
\hline & & Right & Left & \\
\hline \multicolumn{5}{|l|}{ Surgical intervention to complete the $1^{\text {st }}$ Ponseti method } \\
\hline Percutaneous TA tenotomy & Yes & 12 & 16 & 28 \\
\hline Surgical complication & No & 3 & 3 & 6 \\
\hline Methods of bracing to prevent recurrence following correction of CTEV by $1^{\text {st }}$ Ponseti method & Yes & 0 & 0 & 0 \\
\hline Denis Browne FAO only & Yes & 4 & 3 & 7 \\
\hline Compliance & Yes & 3 & 3 & 6 \\
\hline Relapse clubfoot & Yes & 1 & 1 & 2 \\
\hline AFO only & Yes & 8 & 13 & 21 \\
\hline Compliance & Yes & 1 & 4 & 5 \\
\hline Relapse clubfoot & Yes & 5 & 7 & 12 \\
\hline Combination of FAO and AFO & Yes & 3 & 3 & 6 \\
\hline Compliance & Yes & 1 & 1 & 2 \\
\hline Relapse clubfoot & Yes & 1 & 1 & 2 \\
\hline Relapse CTEV after $1^{\text {st }}$ Ponseti method correction types of relapse CTEV & Yes & 7 & 9 & 16 \\
\hline Equinus only & Yes & 7 & 4 & 11 \\
\hline Repeated $2^{\text {nd }}$ percutaneous TA tenotomy done for relapse with residual equinus after $2^{\text {nd }}$ & Yes & 7 & 7 & 14 \\
\hline \multicolumn{5}{|l|}{ Ponseti method } \\
\hline Any complication & Yes & 0 & 0 & 0 \\
\hline Corrective relapse CTEV with $2^{\text {nd }}$ Ponseti method only & Yes & 0 & 2 & 2 \\
\hline Relapse CTEV after $2^{\text {nd }}$ Ponseti method & Yes & 0 & 2 & 2 \\
\hline Compliance & Yes & 0 & 0 & 0 \\
\hline
\end{tabular}

TA: Tendo Achilles, CTEV: Congenital talipes equinus varus, FAO: Foot abduction orthoses, AFO: Ankle-foot orthoses

5 right feet, 9 left feet, and 10 bilateral feet that were successfully corrected using Ponseti method and fulfill the inclusion criteria. A total of 18 children ( 21 feet) used AFO, 4 children ( 7 feet) used Denis Browne shoes with bar, and 3 children ( 6 feet) used a combination of both bracing. The mean follow-up was $4.2 \pm 1.78$ years; range $1-7$ years) with a mean age at presentation being $12.37 \pm 12.22$ weeks (29 days40 weeks). Characteristic of sociodemographic respondent shown male patients were 23 (23 patients) and female patients were 2 (2 patients). Percutaneous tendon Achilles tenotomies were performed on 28 of 34 feet, comprising $82 \%$ for the initial Ponseti method. Initial relapse was noted in 16 clubfeet (47.06\%) following completed Ponseti method (Table 2).

\section{Data analysis}

Data regarding patient demographic features, history, clinical features and Pirani score, duration of serial casting and method of bracing were retrieved from patient's case note. Data collected were coded and analyzed using SPSS 16.0.

Ethics

Ethical approval was obtained from the board of ethical committee of the hospital before initiation of the study.

\section{RESULTS}

Most of the relapses were equinus (11 feet) with a combination of forefoot adduction ( 5 clubfeet). Re-tenotomies were done in 14 clubfeet out of 16 clubfeet following second serial Ponseti casting. Two clubfeet (5.9\%) developed relapse following second serial casting and both the patients were non-compliant to bracing. These two cases which relapsed had equinus deformities and required repeat tenotomies. There was no documented complication following tenotomy. 
The assessment during the latest follow-up showed residual forefoot adduction in 3 feet. One patient (left foot) had persistent forefoot adduction, lateral curvature heel in varus and equinus. Three feet had smaller size compared to the normal foot. A total of 33 feet (97\%) had good and satisfactory results (Table 3). In our study, only one foot (left clubfoot) had a poor result with persistent equinus and heel in varus, and further posterior-medial release and Z-lengthening of tendon Achilles was done.

Mean duration of wearing Dennis Brown abduction orthosis per day was $15.54 \pm 6.09 \mathrm{~h}(6-23 \mathrm{~h})$ and mean for AFO was $16.74 \pm 4.54 \mathrm{~h}(10-23 \mathrm{~h})$. The mean initial Pirani score was 2.18 and the post-correction mean score was 0.19 . There was a significant difference in the mean of Pirani score before and after treatment $(\mathrm{p}<0.05)$ for curvature of lateral border, medial crease, posterior crease, RE, lateral head of talus, and EH (Table 4).

Mean number of cast for first Ponseti method was 5.56 \pm 1.83 (4-8 casts) and mean for the second Ponseti method was 4.8 \pm 2.11 (2-6 casts).

Table 3: Results showed the characteristics of leg, ankle, and foot assessment and parents' perceptions questionnaires

\begin{tabular}{|c|c|c|c|}
\hline \multirow[t]{2}{*}{ Characteristic } & \multicolumn{2}{|c|}{ Clubfoot } & \multirow[t]{2}{*}{ Total } \\
\hline & Right & Left & \\
\hline \multicolumn{4}{|c|}{ Any problem when standing or walking? } \\
\hline No & 16 & 18 & 34 \\
\hline \multicolumn{4}{|c|}{ Forefoot adduction } \\
\hline Yes & 1 & 2 & 3 \\
\hline No & 15 & 16 & 31 \\
\hline \multicolumn{4}{|l|}{ Lateral curvature } \\
\hline Yes & 0 & 1 & 1 \\
\hline No & 15 & 18 & 33 \\
\hline \multicolumn{4}{|l|}{ Heel in varus } \\
\hline Yes & 0 & 1 & 1 \\
\hline No & 15 & 18 & 33 \\
\hline \multicolumn{4}{|l|}{ Joint equinus } \\
\hline Yes & 0 & 1 & 1 \\
\hline No & 15 & 18 & 33 \\
\hline \multicolumn{4}{|c|}{ Calf muscle size inequality } \\
\hline Yes & 1 & 0 & 1 \\
\hline No & 15 & 18 & 33 \\
\hline \multicolumn{4}{|c|}{ Foot size inequality } \\
\hline Yes & 2 & 1 & 3 \\
\hline No & 14 & 17 & 31 \\
\hline \multicolumn{4}{|c|}{$\begin{array}{l}\text { Post Ponseti method parents' perception } \\
\text { questionnaire }\end{array}$} \\
\hline Good & 5 & 9 & 14 \\
\hline Satisfactory & 11 & 8 & 19 \\
\hline Poor & 0 & 1 & 1 \\
\hline
\end{tabular}

There were six clubfeet undergone re-tenotomies without recasting. There was no significant correlation between number of cast and Pirani score $p>0.05$. Number of cast versus Pirani score before and after treatment were weak, $\mathrm{R}^{2}=0.022$ or $2.2 \%$ and $\mathrm{R}^{2}=0.107$ or $10.7 \%$, respectively (Figs. 2 and 3).

\section{DISCUSSION}

CTEV if left untreated, it can be a very disabling condition and being one of the most common deformities seen at birth. It can be one of the contribution factors for the postnatal depression especially mothers living in the newly developing country [5]. In 1950, Ignacio Ponseti a Spanish physician, at the University of Iowa, developed a method of treating clubfoot by manipulation and casting. It is a non-operative treatment which involves gentle serial manipulation, a specific technique of cast application designed to diminish the pathoanatomical abnormalities of the CTEV and a possible percutaneous Achilles tenotomy at the end of the procedure to correct the equinus [6]. In general, this method is well tolerated by almost all patients with CTEV. Furthermore, this method has successfully correct the foot deformity by achieving plantigrade, painless and functional foot without requiring surgical release in $85-90 \%$ of cases $[8,9]$. The correction achieved is long lasting, with few of the patients having follow-up into the fourth or fifth decade of life [6].

Hussain et al. performed a complete subcutaneous tenotomy of tendonAchilles in 12 clubfoot patients to fully the correct of equinus deformity and was followed up for 4 years [10]. Good or excellent results were achieved in $78 \%$ of the patients. The study shows the effectiveness of complete subcutaneous tenotomy of the Achilles tendon in the management of resistant clubfeet treated with plaster of paris casts. The study recommends early subcutaneous tenotomy of the Achilles tendon for resistant equinus deformity after successfully treated the forefoot adduction and hindfoot varus. In our study, initial Ponseti method revealed that 28 clubfeet $(82.35 \%)$ out of 34 clubfeet need percutaneous Achilles tenotomy to correct the equinus deformity and $14(41.18 \%)$ clubfeet need re-tenotomies to achieve good correction.

Cooper and Dietz, in a review of the cases of 45 patients who had been treated by Ponseti and followed for a mean of 30 years, found out that with the use of functional limitation and pain as the outcome criteria, 35 patients (78\%) had achieved an excellent or good outcome [11]. In most of the study using the Ponseti method advising to start the correction as soon as possible $[3,6,8,12]$. The patients who presented to our clinic were in the age group between 29 days and 40 weeks (mean age $12.37 \pm 12.22$ weeks). This was due to initial treatment started at another center.

The reported incidence of residual deformity following treatment with the Ponseti method is anywhere between $1 \%$ and $35 \%$ of feet [11].

Table 4: Mean comparison of Pirani score before and after treatment (paired t-test)

\begin{tabular}{|c|c|c|c|c|c|c|}
\hline Hindfoot contracture score & $\mathbf{n}$ & Mean \pm SD & $\mathbf{t}$ & $\mathbf{p}$ & Correlation & $\mathbf{p}$ \\
\hline CLB_before & 34 & $0.43 \pm 0.33$ & 7.56 & $0.001^{* *}$ & - & - \\
\hline CLB_after & 34 & $0.00 \pm 0.00$ & & & & \\
\hline MC_before & 34 & $0.44 \pm 0.32$ & 4.65 & $0.001^{* *}$ & -0.12 & 0.51 \\
\hline MC_after & 34 & $0.12 \pm 0.22$ & & & & \\
\hline PC_before & 34 & $0.40 \pm 0.32$ & 7.22 & $0.001^{* *}$ & - & - \\
\hline PC_after & 34 & $0.00 \pm 0.00$ & & & & \\
\hline RE_before & 34 & $0.49 \pm 0.31$ & 6.70 & $0.001^{* *}$ & 0.02 & 0.91 \\
\hline LHT_before & 34 & $0.26 \pm 0.35$ & 4.37 & $0.001^{* *}$ & - & - \\
\hline LHT_after & 34 & $0.00 \pm 0.00$ & & & & \\
\hline EH_before & 34 & $0.16 \pm 0.29$ & 3.20 & $0.001^{* *}$ & - & - \\
\hline EH_after & 34 & $0.00 \pm 0.00$ & & & & \\
\hline Pirani_score_before & 34 & $2.18 \pm 1.60$ & 6.98 & $0.001^{* *}$ & -0.06 & 0.73 \\
\hline Pirani_score_after & 34 & $0.19 \pm 0.35$ & & & & \\
\hline
\end{tabular}

**Significant different $\mathrm{p}<0.05$. CLB: Curvature of lateral border, MC: Severity of medial crease, PC: Severity of posterior crease, RE: The severity of equinus, EH: The emptiness of the heel, SD: Standard deviation 


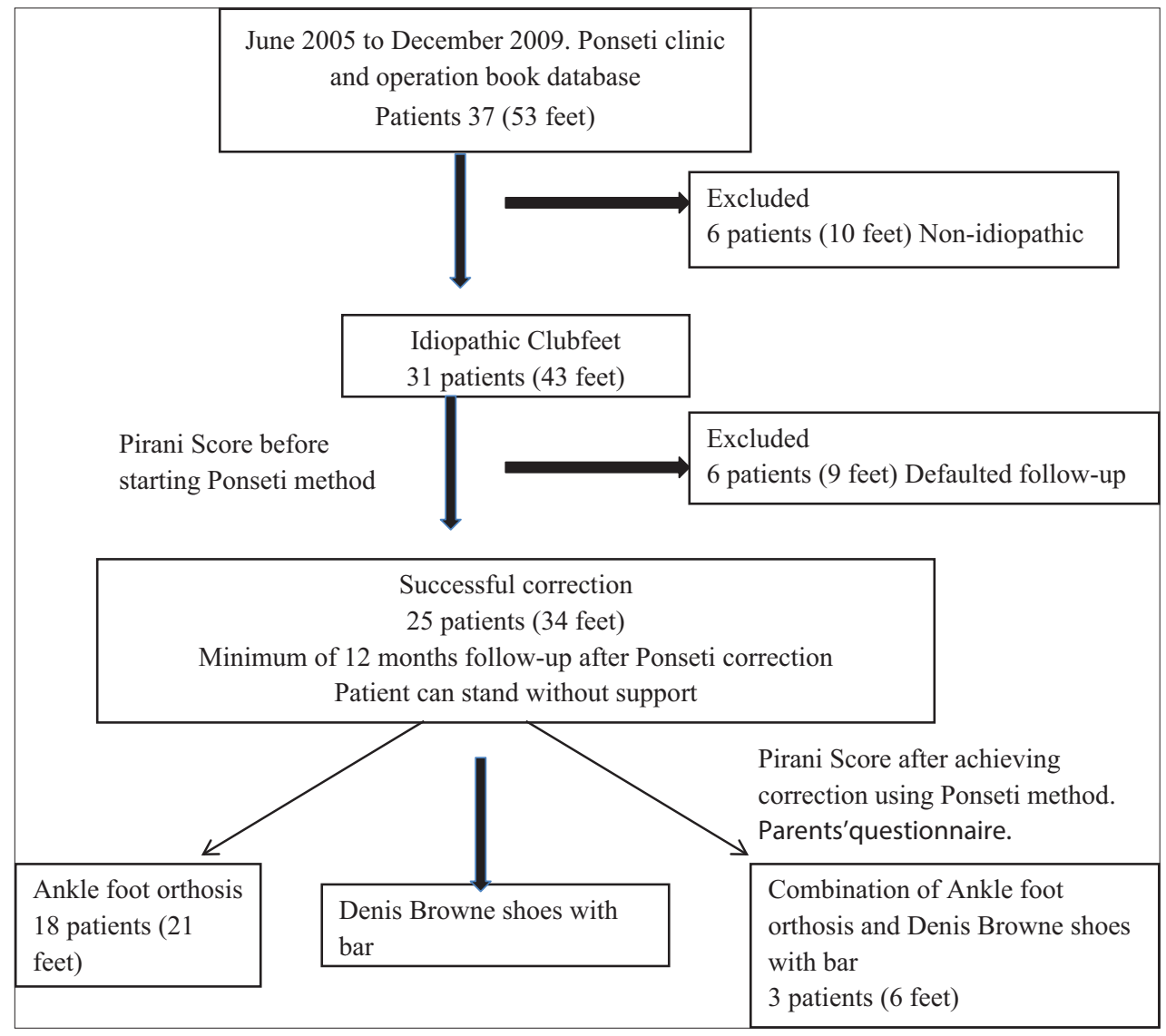

Fig. 1 : Flowchart of patients in the study

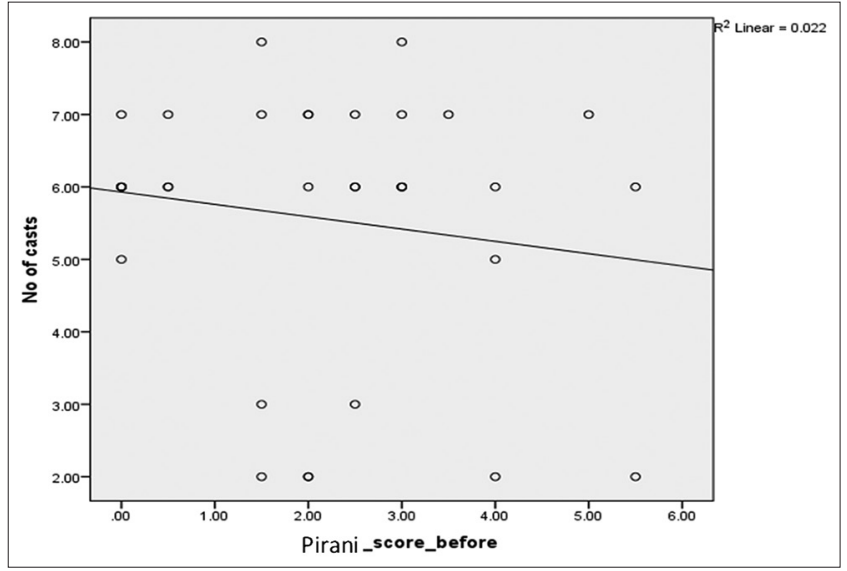

Fig. 2 : Correlation of the number of cast versus Pirani score before treatment is weak, $\mathrm{R}^{2}=0.022$ or $2.2 \%$

In our study, the residual deformity was $14 \%$. Even though in 16 feet $(47.06 \%)$ there was relapse after first Ponseti method and in 7 feet $(20.59 \%)$ there was relapse after second Ponseti; we still achieved $97 \%$ good and satisfactory results. Only one foot (left clubfoot) having persistent equinus and heel in varus despite undergone second Ponseti method and re-tenotomies. This patient was subjected to surgical intervention, posterior medial release of left ankle and z-plasty lengthening of tendon Achilles.

In Ponseti method he defined a relapse as any returns of clubfoot component consist of adductus, cavus, varus, or equinus. The main factor leading to relapse was compliance to maintain corrected clubfoot using shoes with abduction brace $[6,13]$. Our study revealed that the

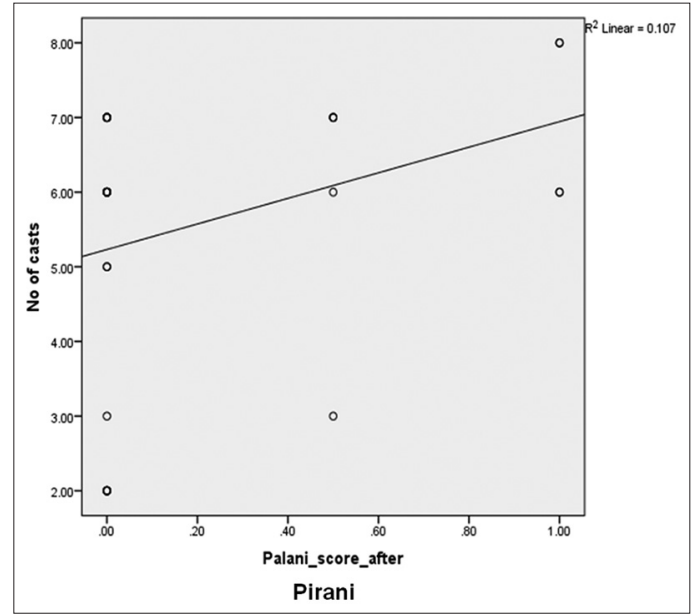

Fig. 3 : Correlation of the number of cast versus Pirani score after treatment is weak, $R^{2}=0.107$ or $10.7 \%$

parents had difficulty in maintaining the FAO inappropriate time for their child and unresolved issue regarding the fitting and compliance. Repeated re-enforcement and education of the necessity of wearing the FAO on regular follow-up failed to improve the compliance. Future success in maintenance of foot correction may require improved compliance with the FAO protocol. Our current strategies to enhance compliance involve the importance of reinforcement at every visit for cast treatment and monitor the shoes fitting on every visit. Patients scheduled for a visit need to be frequent until we are sure the parents and patient are compliance. Financial support is also important to make sure all clubfoot patients can wear Denis Brown shoes with abduction 
splint after completed Ponseti method as in our study only 7 patients (28\%) wore these shoes. 18 patients $(72 \%)$ could not afford to buy Denis Brown shoes FAO due to financial constraint, so there were given AFO instead, and most of the patients were treated before 2008. Option of using a dynamic FAO (Dobbs bar) was also been suggested to improve bracing compliance, but the initial cost in the implementation of these orthosis is much higher than traditional FAO $[14,15]$.

Other options that routinely being used in others developing countries are Steenbeek Foot Abduction Brace (SFAB). It has showed that SFAB is effective in maintaining the correction and can be a cost-effective treatment in compare to the other expensive brace especially its usage in developing countries [16].

We found that there was no significant linear relationship between the initial Pirani scores and number of casts showed same results to that of an earlier study [17]. Our study revealed that there was no positive correlation between initial Pirani score and number of cast. The initial Pirani score was lower due to most of the patients are treated at other center before continuing the treatment at UKMMC

Data from our study suggested that all centers conducted the Ponseti method must have standardized protocol to minimized the possibility of relapse clubfoot. The center also must have proper clubfoot clinic setup and with proper equipment and dedicated team to monitor the progress of treatment to prevent defaulter and for further clinic transfer as necessary rather than referral due to failed Ponseti method.

The sample of this study was small and not significant enough to further analyzed the important of sociodemographic presentation. Most of the patients (22 pts, 88\%) already had the initial treatment done at other center before referral to UKMMC. These samples were not so much representing the actual pre-Ponseti and the age of presentation also a little bit older. Furthermore, we had 6 patients defaulted follow-up after completed initial Ponseti method and patients have difficulty in attending a clinical review session as most of the cases are under yearly follow-up. The data also were not well documented in the case notes especially the Pirani score (3 cases) before starting the Ponseti method.

\section{Limitation of the study}

This study needs larger sample size with a longer period of follow-up. For every patient, a standardized clinical data and proper documentation of Pirani score at initial and on every visit while starting Ponseti serial casting will ensure proper data collection for subsequent study in the future.

\section{CONCLUSION}

Ponseti method is a good and reliable method to achieve correction of CTEV. However, the success of the treatment depends on maintenance and compliance toward FAO and Denis Brown shoes. Parents must be informed or educated on the importance of compliance toward Denis Brown shoes to achieve a good outcome.

\section{ACKNOWLEDGMENT}

The authors would like to thank Dr. Abdul Muhaimin Ali and Dr. Ayesyah Abdullah for the technical help.

\section{AUTHORS CONTRIBUTION}

All the authors contributed equally to conductance of the study, writing and editing the article.

\section{CONFLICTS OF INTERESTS}

None of the authors have any conflicts of interest to be declared.

\section{REFERENCES}

1. Tachdjian MO. The foot and leg. In: Tachdjian Mo. Pediatric Orthopaedic. $2^{\text {nd }}$ ed. Philadelphia, PA: WB Saunders; 1990. p. 2405-3012.

2. Ballantyne JA, Macnicol MF. Clubfoot: An overview of the aetiology and treatment. Curr Orthop 2002;16:85-95.

3. Ponseti IV, Smoley EN. Congenital clubfoot: The results of treatment. J Bone Joint Surg (Am) 1963;45:261-75.

4. Pirani S, Outerbridge H, Moran M, Suwatsky B. A Method of Assessing the Virgin Clubfoot. Orlando, FL: POSNA. 1995.

5. Hashim M. Prevalence of postnatal depression and associated risk factors among South Asian mothers living in a newly developing country. Asian J Pharm and Clin Res 2016;9:57-61.

6. Ponseti IV. Congenital Clubfoot: Fundamentals of Treatment. Oxford: Oxford University Press; 1996.

7. Herzenberg JE, Radler C, Bor N. Ponseti versus traditional methods of casting for idiopathic clubfoot. J Pediatr Orthop 2002;22:517-52.

8. Abbas M, Qureshi OA, Jeelani LZ, Azam Q, Khan AQ, Sabir AB. Management of congenital talipes equinovarus by ponseti technique: A clinical study. J Foot Ankle Surg 2008;47:541-45.

9. Laaveg SJ, Ponseti IV. Long-term results of treatment of congenital clubfoot. J Bone Joint Surg (Am) 1980;62:23-31.

10. Hussain N, Khan T, Ahmed A. Complete subcutaneous tenotomy of tendo-achilles in clubfoot patients-a four year follow up. J Surg 2004;1:17-9.

11. Ikeda K. Conservative treatment of idiopathic clubfoot. J Pediatr Orthop 1992;12:217-23.

12. Cooper DM, Dietz FR. Treatment of Idiopathic clubfoot: A thirty year follow-up. J Bone Joint Surg (Am) 1995;77:1477-89.

13. Dobbs MB, Rudzki JR, Purcell DB, Walton T, Porter KR, Grunett CA. Factors predictive of outcome after use of the Ponseti method for the treatment of idiopathic clubfeet. J Bone Joint Surg (Am) 2004;86:22-7.

14. Chen RC, Gordon JE, Luhmann SJ, Schoenecker PL, Dobbs MB. A new dynamic foot abduction orthosis for clubfoot treatment. J Pediatr Orthop 2007;27:522-8.

15. Garg S, Porter K. Improved bracing compliance in children with clubfoot using a dynamic orthosis. J Child Orthop 2009;3:271-6.

16. Sai DT, Prem K. Steenbeek foot abduction brace for clubfoot: Cost effective but is it effective? A prospective study. Asian J Pharm and Clin Res 2017;10:99-102.

17. Dyer PJ, Davis N. The role of the Pirani scoring system in the management of club foot by the Ponseti method. J Bone J Surg (Br) 2006;88:1082-4. 